\title{
Bat Conservation International
}

Bats constitute approximately one quarter of the world's mammal species and are found worldwide except for the polar regions and the smallest remote islands. They are especially vulnerable to environmental change and human disturbance due to their slow reproductive rates (normal maximum of one per year) and to their tendency to form large aggregations in roosts, such as caves, in which they are easily killed. Their colonies are the largest found in either birds or mammals.

Despite widespread ignorance and superstitious fear, most bats are harmless and highly beneficial. Many plants, including crop species, depend on bats for pollination or seed dispersal. For example, bananas, mangos, avocados, guavas, breadfruit, cloves and some peppers were originally dependent upon certain bats; and kapok, balsa wood, tequila liquor, and sisal hemp 'come from plants that continue to be bat dependent. Insectivorous bats eat vast numbers of insects, including many economic pests. Additionally, bats are eaten by people, and their guano is an important fertiliser in many countries.

Bat populations are declining rapidly, and extinctions were already recorded some $\mathbf{4 0}$ years ago. Large declines and extinctions continue at alarming rates. In recognition of these facts the Species Survival Commission of the International Union for Conservation of Nature and Natural Resources (IUCN) formed a Chiroptera Specialist Group in 1975. An action programme for the conservation of endangered bats was developed with financial aid from the World Wildlife Fund (WWF), and the Fauna and Flora Preservation Society (ffPS) has supported the operation of the Chiroptera Group. Nevertheless, due to recent shortage of conservation money, projects have not received funding despite recognition of their high priority.

Bat Conservation International was founded to raise funds for bat conservation projects worldwide. The aim is to prevent extinction of species, to ensure survival of viable populations, and to improve public awareness and appreciation of the role of bats. These aims will be accomplished through implementation of conservation measures based on previous experience, education at all levels of society, and when necessary, research to establish conservation requirements.

Development of an action programme will continue to follow the criteria established by IUCN/WWF, and priorities will be assigned based on need and practicality. Our first project, financed for one year by the Vincent Wildlife Trust, enabled the employment of a fulltime programme manager who has begun producing educational publications. These materials are being reviewed for accuracy by a panel of distinguished scientists prior to publication and will be distributed to the media, governmental and private organisations, scientists, and other individuals.

Bat Conservation International is a group of the ffPS with offices in Great Britain and the United States, where it is incorporated, enabling tax deductible contributions for projects. Honorary Project Directors are: Dr Harold J. Coolidge, (USA); Rt. Hon. Lord Craigton, (UK); The Earl of Cranbrook, (UK); Lorrie Otto, (USA); Lady Jean Philipps, (UK); Verne Read, (USA); Sir Peter Scott, (UK); and Christine Stevens, (USA).

Project co-ordinators: Dr R.E. Stebbings, ITE, Monks Wood, Abbots Ripton, Huntingdon, PE17 2LS; Dr M.D. Tuttle, Milwaukee Public Museum, 800 West Wells Street, Milwaukee, Wisconsin, USA. 